\title{
CHEMOSPHERE
}

\section{Application of microwave extraction for the evaluation of bioavailability of rare earth elements in soils}

\author{
Anxiang Lu, Shuzhen Zhang, Xiao-quan Shan *, Songxue Wang, Zhongwen Wang \\ Research Center for Eco-Environmental Sciences, Chinese Academy of Sciences, P.O. Box 2871, Beijing 100085, China
}

Received 3 February 2003; received in revised form 28 May 2003; accepted 15 June 2003

\begin{abstract}
A single microwave extraction procedure was conducted to investigate the bioavailability of rare earth elements (REEs) by using different extractants of $0.05 \mathrm{M}$ EDTA, $0.10 \mathrm{M} \mathrm{CH}_{3} \mathrm{COOH}, 0.10 \mathrm{M} \mathrm{HCl}$, and $0.05 \mathrm{M} \mathrm{CaCl}_{2}$. The experimental conditions of heating time and microwave power were optimized. A microwave power of $60 \%$ and extraction time of $30 \mathrm{~min}$ were adopted. Compared to the conventional single extraction schemes reported in the literature, the recommended technique shortened the operational time, simplified the experimental task, improved the precision, and obtained consistent results with those obtained by using the conventional methods. In addition, the suggested microwave extraction method has been successfully used to evaluate the bioavailability of REEs in soils. Soil samples collected from 15 sites in China were extracted by four different extractants with microwave ancillary. Extractable REEs from soils were well correlated with REEs contents in shoots of wheat (Troticum aestivum L.) under the greenhouse conditions. The correlation coefficients were $0.6514-0.8996,0.4522-0.7783,0.6506-0.8671,0.4869-0.7014$ between the extractable REEs in soils and their concentrations in wheat shoots for the extractants of $\mathrm{CaCl}_{2}, \mathrm{EDTA}, \mathrm{CH}_{3} \mathrm{COOH}$ and $\mathrm{HCl}$, respectively.
\end{abstract}

(C) 2003 Elsevier Ltd. All rights reserved.

Keywords: Microwave; Single extraction; Rare earth elements; Bioavailability

\section{Introduction}

Over the past decades rare earth elements (REEs) have been widely applied in industry and agriculture. Particularly, millions of tons of fertilizers containing REEs were used worldwide due to the increase of agricultural productivity. Since early 1990s commercial microfertilizers containing REEs have been applied in China and were estimated to cover approximately farm land of $3.3 \times 10^{7}$ ha until 1999 . The use of REE-fertilizer is still increasing and will reach $1.3 \times 10^{8}$ ha until 2004 .

\footnotetext{
${ }^{*}$ Corresponding author. Tel.: +86-10-6292-3560; fax: +8610-6292-3653.

E-mail address: xiaoquan@mail.rcees.ac.cn (X.-q. Shan).
}

The widespread use of REEs in agriculture might become a critical environmental problem in China.

Many efforts have been made to understand the distribution and accumulation of REEs in the environment (Ichihashi et al., 1992; Tu et al., 1994; Wyttenbach et al., 1998). Although the total concentration of REEs in soils affords valuable information about overall pollution levels, it is insufficient to estimate the bioavailability of REEs, which depends on the chemical speciation of REEs in soils and plant species (Zhang and Shan, 2001; Hu et al., 2002). Therefore, it is important to obtain information of elemental speciation in soils. Both single and sequential extraction procedures provide information on the potential mobility and bioavailability of REEs. Sequential extraction approaches provide more detailed information about the different availabilities of heavy metals and REEs among different 
geochemical phases (Tessier et al., 1979; Quevauiller et al., 1993). But as we know not all the fractions are equally important in bioavailability assessment. The stable fractions present in the residues are unlikely to be released under soil-weathering conditions. Whereas water-soluble, exchangeable metal species are quite mobile and bioavailable to plants. To assess the bioavailability of metals in soils, therefore, efforts should be concentrated on these available fractions. For this purpose many single extraction methods have been developed and applied to investigate the bioavailability and/ or toxicity of metals in soils (Das et al., 1995; Rauret, 1998). The frequently used leaching reagents can be grouped into four categories: dilute acids (including organic acids or inorganic acids), chelating agents, unbuffered salt solutions, and buffered salt solutions (Ure et al., 1993; Ginepro et al., 1996).

Microwave energy is a very useful form of auxiliary energy that has been widely applied in analytical chemistry (Jin et al., 1999; Parkes and Barnes, 1999; Jayaraman et al., 2001). In recent years, microwave extraction techniques have been introduced to the speciation study of metals in geological and environmental samples in order to simplify extraction procedures and shorten the treatment time (Cid et al., 2001). However, whether the microwave extraction methods could be used to evaluate the mobility and bioavailability of heavy metals in soil or sediment is still lack of evidence.

In this work, single microwave extraction was applied to assess the bioavailability of REEs in soils by using different extractants $\mathrm{CaCl}_{2}$, EDTA, $\mathrm{CH}_{3} \mathrm{COOH}$ and $\mathrm{HCl}$. The microwave operating conditions, such as heating time and power, were optimized. The relationship between the fractionation of REEs in soil pools performed by microwave extraction and the accumula- tion by plants was established to evaluate the plant availability of REEs in soils.

\section{Experimental}

\subsection{Soils}

Soil samples $(0-20 \mathrm{~cm})$ were collected from 15 rural regions in China, representing typical Chinese soils with different physicochemical properties. The soil samples were ground to pass through a $2 \mathrm{~mm}$ sieve, homogenized and stored until analysis. Soil properties of $\mathrm{pH}$, organic matter (OM) and cation exchange capacity (CEC) were determined using standard methods (Lau, 1988). These properties are given in Table 1.

\subsection{Greenhouse experiment}

The air-dried soil samples were first treated with $0.04 \% \mathrm{~N}$ and $\mathrm{P}$, as solution of $\mathrm{KH}_{2} \mathrm{PO}_{4}$ and $\left(\mathrm{NH}_{4}\right)_{2} \mathrm{CO}_{3}$. After the soil and solution were mixed thoroughly, the soils were air-dried again and ground to sieve a $1 \mathrm{~mm}$ mesh. A portion of $1.5 \mathrm{~kg}$ of the treated soil was added to plastic pot (Wang et al., 2001).

Wheat seeds (Troticum aestivum L.) were thoroughly rinsed with water, and germinated on the filter paper. After wheat seeds were germinated for $24 \mathrm{~h}$ at $20^{\circ} \mathrm{C}$ in the dark, uniformly germinated seeds with radical emerged were sown in soil, which had been left in pots to equilibrate overnight. Thirty seeds were sown per pot and subsequently thinned to 20 plants. Plants were grown under the greenhouse conditions of temperature ranged from 20 to $25^{\circ} \mathrm{C}$ during the day and 8 to $15^{\circ} \mathrm{C}$

Table 1

Selected properties of soils

\begin{tabular}{lllll}
\hline Sample & Site & $\mathrm{pH}$ & $\mathrm{CEC}^{\mathrm{a}}\left(\mathrm{cmol} \mathrm{kg}^{-1}\right)$ & $\mathrm{OM}^{\mathrm{b}}(\%)$ \\
\hline 1 & Jiamusi & 5.97 & 27.03 & 4.30 \\
2 & Lanzhou & 7.43 & 10.68 & 2.53 \\
3 & Xian & 8.25 & 25.88 & 1.75 \\
4 & Taiyuan & 7.92 & 21.86 & 4.12 \\
5 & Yuxi & 4.45 & 25.78 & 1.37 \\
6 & Kunming & 5.55 & 26.74 & 3.22 \\
7 & Jinan & 5.94 & 30.20 & 1.53 \\
8 & Nanchang & 5.49 & 14.24 & 3.02 \\
9 & Shanghai & 5.53 & 36.65 & 3.28 \\
10 & Hanzhou & 7.05 & 19.76 & 2.03 \\
11 & Kaifeng & 7.73 & 18.12 & 2.37 \\
12 & Wuhan & 7.27 & 53.98 & 2.28 \\
13 & Changsha & 5.50 & 43.11 & 2.09 \\
15 & Hefei & 6.71 & 24.95 & 1.37 \\
\hline
\end{tabular}

${ }^{\text {a }}$ Cation-exchange capacity.

${ }^{\mathrm{b}}$ Organic matter. 
during the night. The water content of soils was kept around $15 \%$ by adding deionized water daily.

Plants were harvested eight weeks after germination. The aboveground parts of the plants were first harvested as shoots. The shoots were then rinsed with deionized water and dried at $60{ }^{\circ} \mathrm{C}$ for $48 \mathrm{~h}$. Then, the dried sample was finely ground for REEs analysis.

\subsection{Single extraction procedure}

Many reagents have been used in single extractions, ranging from very strong acids, such as aqua regia, nitric acid, or hydrochloric acid, to neutral unbuffered salt solutions, mainly $\mathrm{CaCl}_{2}$ or $\mathrm{NaNO}_{3}$, and other extractants, e.g. buffered salt solution or complexing agents, are also frequently used, because of their capacity to form stable water-soluble complexes with a wide range of cations. In this experiment, $0.05 \mathrm{moll}^{-1} \mathrm{CaCl}_{2}, 0.05$ moll ${ }^{-1}$ EDTA, $0.10 \mathrm{moll}^{-1} \mathrm{CH}_{3} \mathrm{COOH}$ and $0.10 \mathrm{moll}^{-1}$ $\mathrm{HCl}$ were used, respectively, representing typical extractants with different properties of acid extraction, organic acid, unbuffered salt solution and chelating agents.

For microwave extraction a portion of $1.000 \mathrm{~g}$ of wet rhizosphere soil was weighed immediately and put into the microwave vessel after sampling and homogenizing (Wang et al., 2002), $20 \mathrm{ml}$ of $0.05 \mathrm{moll}^{-1} \mathrm{CaCl}_{2}$ or 0.05 $\mathrm{moll}^{-1}$ EDTA or $0.10 \mathrm{moll}^{-1} \mathrm{CH}_{3} \mathrm{COOH}$, or 0.10 mol $1^{-1} \mathrm{HCl}$ was added. Prior to the heating step, the soil sample and the extractant were homogenized using a magnetic shaker for $5 \mathrm{~s}$ and then the soil-liquid mixture was immediately exposed to microwave (CEM Digestion System Model MDS 2000 with maximum power of 630 W, CEM Corporation Matthews, NC). The microwave power and extraction time were optimized. After microwave extraction, the supernatant were centrifuged and filtered through a filter of $0.45 \mu \mathrm{m}$ pore size. All the extraction was carried out in triplicate and the average values were used for data analysis.

For conventional extraction, triplicate $1.000 \mathrm{~g}$ of the soil sample was weighed into a $50 \mathrm{ml}$ polypropylene tube and $20 \mathrm{ml}$ of extraction solution was added. The samples were then shaken for $16 \mathrm{~h}$ for $\mathrm{CH}_{3} \mathrm{COOH}, 2 \mathrm{~h}$ for $\mathrm{CaCl}_{2}$, $\mathrm{HCl}$ and EDTA at room temperature. The extracted samples were centrifuged and filtered through a filter of $0.45 \mu \mathrm{m}$ pore size, and the filtrate was used for final determination.

\subsection{Determination of REES}

Total concentrations of REEs in plants and soils were determined by inductively coupled plasma mass spectrometry (ICP-MS, PQ 3, Fisons Instruments, UK). The optimized instrumental operating conditions are given in Table 2. A portion of $0.1000 \mathrm{~g}$ of soils or $0.2000 \mathrm{~g}$ of plant
Table 2

ICP-MS operating conditions

$\begin{array}{ll}\text { ICP system } & \\ \text { Forward power } & 1350 \mathrm{~W} \\ \text { Reflected power } & <5 \mathrm{~W} \\ \text { Coolant argon flow rate } & 141 \mathrm{~min}^{-1} \\ \text { Auxiliary gas flow rate } & 0.91 \mathrm{~min}^{-1} \\ \text { Nebulizer gas flow rate } & 0.81 \mathrm{~min}^{-1} \\ \text { Sample uptake rate } & 1.01 \mathrm{~min}^{-1} \\ \text { Sampling depth } & 15 \mathrm{~mm} \\ & \\ \text { Mass spectrometer } & 1.0 \mathrm{~mm} \\ \text { Sampler (nickel) orifice } & 0.7 \mathrm{~mm} \\ \text { Skimmer (nickel) orifice } & 5 \times 10^{-7} \mathrm{mbar} \\ \text { Vacuum } & \text { Range-scanning mode } \\ \text { Data acquisition } & 85-175 \mathrm{amu} \\ \text { Mass range } & 60 \mathrm{~s} \\ \text { Total acquisition time } & \end{array}$

samples were decomposed with $3 \mathrm{ml}$ of $\mathrm{HNO}_{3}-\mathrm{HF}-$ $\mathrm{HClO}_{4}(1: 1: 1, \mathrm{v} / \mathrm{v})$ mixture under high pressure conditions (Zhang and Shan, 1997). The range and mean values of the concentrations are presented in Table 3. The extractable REEs obtained by microwave and conventional single extraction were analyzed after the dilution of 10 times with $2 \%$ of $\mathrm{HNO}_{3}$. The results are listed in Table 4.

The precision and accuracy of the elemental analysis were checked by the determination of REEs in the certified reference materials (GSS-1 soil and GBW 07605 tea leaf purchased from the National Research Center for Certified Reference Materials, Beijing, China). Seven replicated analyses were made for each sample. The results are summarized in Table 5. Good agreements were achieved between the data obtained by the present method and the certified values. The high precision of the analysis is also evidenced by the data listed in Table 5 .

All reagents used were of analytical reagent grade or better.

Statistical analysis was performed by use of Office XP-Excel and Origin 6.0.

\section{Results and discussion}

\subsection{Influence of microwave power and microwave heating time upon the extraction efficiency}

To optimize extraction conditions the microwave heating power and time were investigated. Nanchang soil (No. 8) was used in the optimization experiment. Because of the similarity of each REEs, only La was determined representing other REEs. The microwave power was varied from $20 \%$ to $80 \%$ and the microwave heating time was kept constant at $45 \mathrm{~min}$. The results are 
Table 3

Total concentrations of REEs in soils, wheat shoots and roots

\begin{tabular}{|c|c|c|c|c|c|c|}
\hline \multirow[t]{2}{*}{ REEs } & \multicolumn{2}{|c|}{ Concentration in soil $\left(\mu \mathrm{g} \mathrm{g}^{-1}\right)$} & \multicolumn{2}{|c|}{ Concentration in root $\left(\mu \mathrm{g} \mathrm{g}^{-1}\right)$} & \multicolumn{2}{|c|}{ Concentration in shoot $\left(\mathrm{ng} \mathrm{g}^{-1}\right)$} \\
\hline & Range & Mean & Range & Mean & Range & Mean \\
\hline $\mathrm{Y}$ & $13.9-24.7$ & 19.7 & $1.0-5.3$ & 2.8 & $19.8-214.5$ & 52.0 \\
\hline $\mathrm{La}$ & $13.3-41.1$ & 24.2 & $0.7-9.0$ & 4.3 & $53.2-221.9$ & 108.2 \\
\hline $\mathrm{Ce}$ & $29.5-87.5$ & 51.0 & $5.0-16.5$ & 11.3 & $87.6-505.8$ & 199.4 \\
\hline $\operatorname{Pr}$ & $3.1-9.9$ & 5.6 & $0.2-1.8$ & 1.0 & $9.5-60.3$ & 20.8 \\
\hline $\mathrm{Nd}$ & $10.8-36.2$ & 19.8 & $0.6-5.6$ & 3.5 & $29.3-221.1$ & 69.3 \\
\hline $\mathrm{Sm}$ & $4.1-5.7$ & 4.9 & $0.1-1.2$ & 0.7 & $4.6-40.4$ & 10.5 \\
\hline $\mathrm{Eu}$ & $0.9-1.3$ & 1.1 & $0.1-0.3$ & 0.2 & $1.6-19.4$ & 4.4 \\
\hline $\mathrm{Gd}$ & $3.8-5.4$ & 4.7 & $0.2-1.2$ & 0.7 & $3.9-37.7$ & 10.2 \\
\hline $\mathrm{Tb}$ & $0.6-0.8$ & 0.7 & $0.02-0.2$ & 0.09 & $0.6-5.8$ & 1.5 \\
\hline Dy & $3.3-4.8$ & 4.3 & $0.1-0.9$ & 0.5 & $3.2-34.1$ & 8.2 \\
\hline Ho & $0.6-0.9$ & 0.8 & $0.03-0.2$ & 0.1 & $0.6-7.5$ & 1.7 \\
\hline $\mathrm{Er}$ & $1.6-2.6$ & 2.3 & $0.09-0.5$ & 0.3 & $1.6-22.0$ & 4.8 \\
\hline $\mathrm{Tm}$ & $0.2-0.4$ & 0.4 & $0.01-0.06$ & 0.04 & $0.3-3.9$ & 0.8 \\
\hline $\mathrm{Yb}$ & $2.1-2.4$ & 2.2 & $0.1-0.4$ & 0.3 & $1.5-25.3$ & 4.9 \\
\hline $\mathrm{Lu}$ & $0.3-0.4$ & 0.4 & $0.02-0.05$ & 0.04 & $0.3-4.4$ & 0.9 \\
\hline
\end{tabular}

Table 4

Concentration range and mean value of the extractable REEs by different extractants using microwave ancillary

\begin{tabular}{|c|c|c|c|c|c|c|c|c|}
\hline \multirow[t]{3}{*}{ REEs } & \multicolumn{8}{|l|}{ Extractant } \\
\hline & \multicolumn{2}{|c|}{$\mathrm{CaCl}_{2}\left(\mathrm{ng} \mathrm{g}^{-1}\right)$} & \multicolumn{2}{|c|}{ EDTA $\left(\mu \mathrm{gg}^{-1}\right)$} & \multicolumn{2}{|c|}{$\mathrm{CH}_{3} \mathrm{COOH}\left(\mathrm{ng} \mathrm{g}^{-1}\right)$} & \multicolumn{2}{|c|}{$\mathrm{HCl}\left(\mu \mathrm{g} \mathrm{g}^{-1}\right)$} \\
\hline & Range & Mean & Range & Mean & Range & Mean & Range & Mean \\
\hline $\mathrm{Y}$ & $7.5-553.4$ & 144.8 & $2.84-14.4$ & 7.4 & $53.5-262.6$ & 121.4 & $2.1-9.4$ & 5.8 \\
\hline $\mathrm{La}$ & $54.2-932.6$ & 284.9 & $3.2-27.5$ & 8.6 & $91.9-891.1$ & 169.7 & $2.5-28.0$ & 7.6 \\
\hline $\mathrm{Ce}$ & $29.3-1533.1$ & 398.9 & $6.1-35.8$ & 19.6 & $113.6-647.0$ & 254.3 & $4.2-33.7$ & 16.0 \\
\hline $\operatorname{Pr}$ & $4.2-144.6$ & 42.3 & $0.8-4.1$ & 2.3 & $16.6-79.7$ & 34.5 & $0.6-2.9$ & 1.8 \\
\hline $\mathrm{Nd}$ & $13.9-439.9$ & 148.1 & $3.2-16.9$ & 8.4 & $57.9-346.1$ & 141.5 & $2.1-10.0$ & 6.4 \\
\hline $\mathrm{Sm}$ & $4.1-139.0$ & 32.7 & $0.7-3.9$ & 1.9 & $15.6-78.5$ & 34.0 & $0.5-2.2$ & 1.4 \\
\hline $\mathrm{Eu}$ & $2.9-100.3$ & 13.7 & $0.2-1.0$ & 0.4 & $4.6-31.4$ & 10.7 & $0.1-0.5$ & 0.3 \\
\hline $\mathrm{Gd}$ & $4.7-141.1$ & 34.9 & $0.7-3.9$ & 1.9 & $16.4-93.5$ & 33.7 & $0.5-2.2$ & 1.4 \\
\hline $\mathrm{Tb}$ & $0.8-103.5$ & 8.4 & $0.1-0.6$ & 0.3 & $2.5-28.0$ & 6.5 & $0.07-0.3$ & 0.2 \\
\hline Dy & $4.0-131.2$ & 25.1 & $0.5-3.0$ & 1.4 & $13.6-62.3$ & 25.2 & $0.4-1.7$ & 1.1 \\
\hline Ho & $0.8-78.2$ & 7.1 & $0.1-0.6$ & 0.3 & $2.4-19.7$ & 6.0 & $0.07-0.3$ & 0.2 \\
\hline $\mathrm{Er}$ & $1.8-82.3$ & 12.8 & $0.3-1.4$ & 0.7 & $5.7-34.1$ & 13.6 & $0.2-0.8$ & 0.5 \\
\hline $\mathrm{Tm}$ & $0.6-60.6$ & 4.1 & $0.04-0.2$ & 0.1 & $0.9-15.6$ & 3.1 & $0.02-0.1$ & 0.07 \\
\hline $\mathrm{Yb}$ & $1.3-69.6$ & 9.9 & $0.2-1.0$ & 0.5 & $3.4-27.9$ & 12.6 & $0.1-0.6$ & 0.4 \\
\hline $\mathrm{Lu}$ & $0.6-7.3$ & 2.1 & $0.03-0.2$ & 0.09 & $1.0-10.2$ & 2.7 & $0.02-0.1$ & 0.06 \\
\hline
\end{tabular}

shown in Fig. 1. As we can see that when $\mathrm{CaCl}_{2}$, EDTA, and $\mathrm{HCl}$ were applied as extractants, the extractable amount of $\mathrm{La}$ increased with increasing microwave power from $20 \%$ to $80 \%$. But when $\mathrm{CH}_{3} \mathrm{COOH}$ was used as extractant, the extractable amount of La decreased with the power increasing. The reason was probably that when the microwave power increased some evaporation of $\mathrm{CH}_{3} \mathrm{COOH}$ happened and hence the extractable REEs reduced. However, we can see that the extractable contents of La became stable from microwave power $60 \%$ to $80 \%$ no matter what extractant was used. Therefore, the microwave power of $60 \%$ was selected for the remainder of the experiments.
After the microwave power was chosen, the effect of extraction time was studied. The results are shown in Fig. 2. Obviously, the amount of REEs extracted remained unchanged for the extraction time from 25 to 40 min; hence the microwave heating time of $30 \mathrm{~min}$ was selected.

\subsection{Comparison between conventional extraction method and microwave extraction procedure}

After the microwave extraction procedure was optimized, 15 soils were extracted and the concentration ranges and mean values of extractable REEs by different 
Table 5

Determination of REEs in the certified reference materials by inductively coupled plasma mass spectrometry

\begin{tabular}{|c|c|c|c|c|}
\hline \multirow[t]{2}{*}{ REEs } & \multicolumn{2}{|c|}{ GSS-1 soil $\left(\mu \mathrm{g} \mathrm{g}^{-1}\right)$} & \multicolumn{2}{|c|}{ GBW07605 tea leaves $\left(\mu \mathrm{g} \mathrm{g}^{-1}\right)$} \\
\hline & This method & Certified & This method & Certified \\
\hline $\mathrm{Y}$ & $24.7 \pm 0.50$ & $25 \pm 4$ & $0.40 \pm 0.01$ & $0.36 \pm 0.03$ \\
\hline $\mathrm{La}$ & $36.1 \pm 2.6$ & $34 \pm 4$ & $0.62 \pm 0.07$ & $0.60 \pm 0.06$ \\
\hline $\mathrm{Ce}$ & $71.5 \pm 2.8$ & $70 \pm 5$ & $1.05 \pm 0.08$ & $1.0 \pm 0.1$ \\
\hline $\operatorname{Pr}$ & $7.6 \pm 0.3$ & $7.5 \pm 0.5$ & $0.10 \pm 0.02$ & $(0.12)$ \\
\hline $\mathrm{Nd}$ & $26.8 \pm 0.9$ & $28 \pm 3$ & $0.50 \pm 0.06$ & $(0.44)$ \\
\hline $\mathrm{Sm}$ & $5.1 \pm 0.3$ & $5.2 \pm 0.4$ & $0.09 \pm 0.01$ & $0.085 \pm 0.017$ \\
\hline $\mathrm{Eu}$ & $1.0 \pm 0.1$ & $1.0 \pm 0.1$ & $0.02 \pm 0.001$ & $0.018 \pm 0.002$ \\
\hline $\mathrm{Gd}$ & $4.7 \pm 0.2$ & $4.6 \pm 0.3$ & $0.10 \pm 0.003$ & $(0.093)$ \\
\hline $\mathrm{Tb}$ & $0.71 \pm 0.05$ & $0.75 \pm 0.09$ & $0.012 \pm 0.003$ & $(0.011)$ \\
\hline Dy & $4.3 \pm 0.1$ & $4.6 \pm 0.3$ & $0.076 \pm 0.002$ & $(0.074)$ \\
\hline Ho & $0.83 \pm 0.06$ & $0.87 \pm 0.09$ & $0.021 \pm 0.003$ & (0.019) \\
\hline $\mathrm{Er}$ & $2.5 \pm 0.3$ & $2.6 \pm 0.2$ & $0.056 \pm 0.001$ & \\
\hline $\mathrm{Tm}$ & $0.42 \pm 0.04$ & $0.42 \pm 0.07$ & $0.018 \pm 0.002$ & \\
\hline $\mathrm{Yb}$ & $2.6 \pm 0.3$ & $2.66 \pm 0.33$ & $0.048 \pm 0.002$ & $(0.044)$ \\
\hline $\mathrm{Lu}$ & $0.36 \pm 0.02$ & $0.41 \pm 0.06$ & & \\
\hline
\end{tabular}
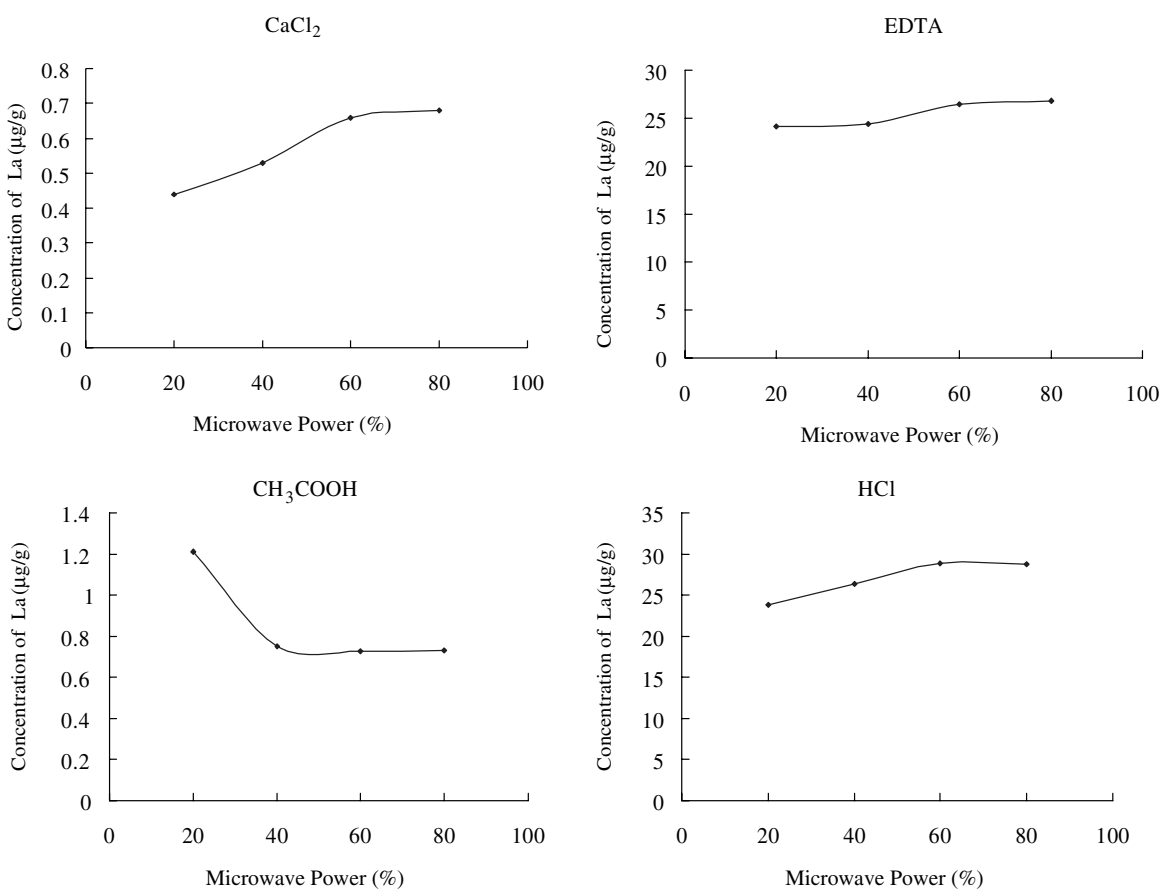

Fig. 1. Influence of microwave power on the REEs extraction efficiency by the extractants $\mathrm{CaCl}_{2} ; \mathrm{CH}_{3} \mathrm{COOH}$; EDTA; $\mathrm{HCl}$.

extractants are listed in Table 4. The extraction efficiency by different reagents follows this order EDTA $>$ $\mathrm{HCl}>\mathrm{CaCl}_{2}>\mathrm{CH}_{3} \mathrm{COOH}$. The extraction percentage is from $22.5 \%$ to $42.8 \%, 15.0 \%$ to $32.3 \%, 4.5 \%$ to $12.5 \%$ and from $5.0 \%$ to $9.73 \%$ for EDTA, $\mathrm{HCl}, \mathrm{CaCl}_{2}$, $\mathrm{CH}_{3} \mathrm{COOH}$, respectively.

The conventional and microwave single extraction methods were compared by using the Nanchang soil
(No. 8). The extraction was carried out in triplicate and the data obtained by conventional and microwave methods were compared. The results are shown in Table 6. We can see that the extraction efficiencies from microwave and conventional extraction were in good agreements for all extractants. In order to see more clearly, the relative extraction efficiencies which were calculated as the percentage of REEs extracted by 

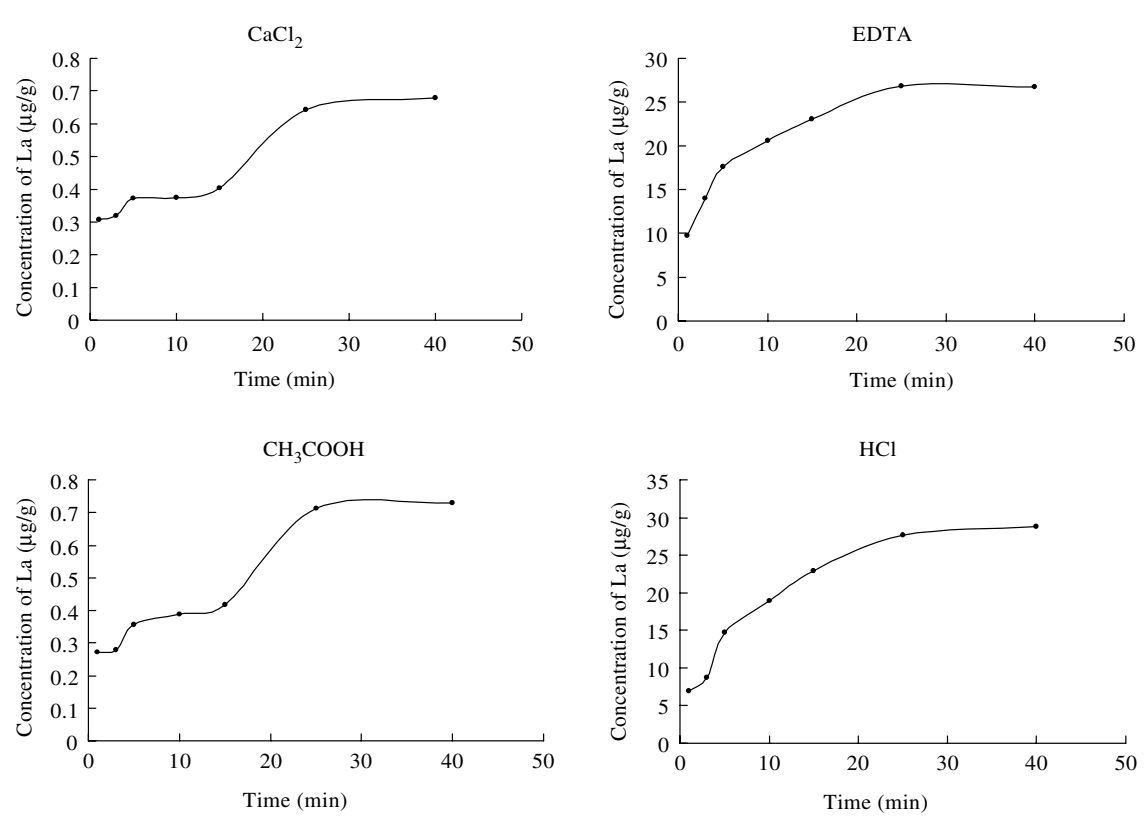

Fig. 2. Influence of microwave heating time on the REEs extraction efficiency by the extractants $\mathrm{CaCl}_{2} ; \mathrm{CH}_{3} \mathrm{COOH}$; $\mathrm{EDTA} ; \mathrm{HCl}$.

microwave single extraction to that leached by the conventional procedure are listed in Table 7 . The relative extraction efficiency was from $89.1 \%$ to $108 \%, 96.0 \%$ to $109 \%, 91.7 \%$ to $109 \%$ and $91.6 \%$ to $112 \%$ for the extractants $\mathrm{CaCl}_{2}, \mathrm{EDTA}, \mathrm{CH}_{3} \mathrm{COOH}$ and $\mathrm{HCl}$, respectively. However, the relative standard deviation (RSD) of microwave extraction procedure was much better than that of the conventional methods. The RSDs of the microwave extraction were from $1.0 \%$ to $6.9 \%$ for different extractants, however, the RSDs of the conventional single extraction methods were from $2.2 \%$ to $10.5 \%$. It is understandable that the operating conditions for microwave extraction are easy to control and is more stable than those of the conventional single extraction.

\subsection{Relationship between the extractable metal fractions and availability to plants}

One of the most important applications of single extraction for metals in soils is to assess the bioavailability of metals to plants. In this work, single correlation analysis was performed in order to investigate the relationship between the extractable contents of REEs in 15 individual soils and the contents in plants. The results are listed in Table 8 . The correlation coefficients are $0.6514-0.8996,0.4522-0.7783,0.6506-0.8671,0.4869$ 0.7014 for shoots and $0.1568-0.4904,0.3204-0.6454$, $0.3945-0.7574,0.1096-0.5938$ for roots, for the extractants of $\mathrm{CaCl}_{2}, \mathrm{EDTA}, \mathrm{CH}_{3} \mathrm{COOH}$ and $\mathrm{HCl}$, respectively. The microwave extractable content of REEs has good correlation with plant shoots. However, only the extractable contents of REEs by the extractants of EDTA and $\mathrm{CH}_{3} \mathrm{COOH}$ correlate with the REEs in roots. Such phenomena that the correlation of shoots is better than that of root have been found in the previous work (Li et al., 1998; Wang et al., 2001). The reasons are still unclear. However, the good correlation between microwave extractable REEs in soils and REEs accumulated in the wheat shoots obtained by this work suggest that microwave extraction could be used to predict the bioavailability of REEs in soils.

\section{Conclusion}

Single extraction method is usually employed to evaluate the possible mobility and bioavailability of heavy metals present in the environmental samples. In this work, the bioavailability of REEs in soils was studied by single microwave extraction, and the results demonstrated that there was a satisfactory correlation between microwave extractable REEs in soils and REEs accumulated in the wheat shoots. This means that single microwave extraction can be used as a convenient method to evaluate the bioavailability of REEs to plants.

According to the results obtained by this work, the single microwave method allows us to obtain similar results to the conventional methods. Compared to the conventional methods, microwave extraction not only substantially reduced the extraction time but also led to 
Table 6

Comparison between the conventional and microwave methods for determination of REEs in soil No. $8\left(n=3, \mu \mathrm{g} \mathrm{g}^{-1}\right)$

\begin{tabular}{|c|c|c|c|c|c|c|c|c|}
\hline \multirow[t]{3}{*}{ REEs } & \multicolumn{8}{|l|}{ Extractant } \\
\hline & \multicolumn{2}{|l|}{$\mathrm{CaCl}_{2}$} & \multicolumn{2}{|l|}{ EDTA } & \multicolumn{2}{|l|}{$\mathrm{CH}_{3} \mathrm{COOH}$} & \multicolumn{2}{|l|}{$\underline{\mathrm{HCl}}$} \\
\hline & $\begin{array}{l}\text { Conventional } \\
\text { method }\end{array}$ & $\begin{array}{l}\text { Microwave } \\
\text { method }\end{array}$ & $\begin{array}{l}\text { Conventional } \\
\text { method }\end{array}$ & $\begin{array}{l}\text { Microwave } \\
\text { method }\end{array}$ & $\begin{array}{l}\text { Conventional } \\
\text { method }\end{array}$ & $\begin{array}{l}\text { Microwave } \\
\text { method }\end{array}$ & $\begin{array}{l}\text { Conventional } \\
\text { method }\end{array}$ & $\begin{array}{l}\text { Microwave } \\
\text { method }\end{array}$ \\
\hline $\mathrm{Y}$ & $0.41 \pm 0.03$ & $0.44 \pm 0.02$ & $11.1 \pm 0.4$ & $11.8 \pm 0.03$ & $0.161 \pm 0.008$ & $0.168 \pm 0.004$ & $6.1 \pm 0.3$ & $6.61 \pm 0.08$ \\
\hline $\mathrm{La}$ & $0.61 \pm 0.02$ & $0.64 \pm 0.02$ & $26.9 \pm 0.9$ & $26.3 \pm 0.4$ & $0.74 \pm 0.06$ & $0.71 \pm 0.01$ & $26.7 \pm 0.8$ & $27.6 \pm 0.6$ \\
\hline $\mathrm{Ce}$ & $1.11 \pm 0.04$ & $1.15 \pm 0.04$ & $28.3 \pm 0.8$ & $28.8 \pm 0.4$ & $0.42 \pm 0.02$ & $0.41 \pm 0.02$ & $19.4 \pm 0.5$ & $17.8 \pm 0.2$ \\
\hline $\operatorname{Pr}$ & $0.12 \pm 0.01$ & $0.115 \pm 0.008$ & $3.37 \pm 0.08$ & $3.31 \pm 0.04$ & $0.045 \pm 0.003$ & $0.049 \pm 0.002$ & $1.80 \pm 0.06$ & $1.94 \pm 0.02$ \\
\hline $\mathrm{Nd}$ & $0.45 \pm 0.02$ & $0.441 \pm 0.008$ & $12.6 \pm 0.4$ & $13.5 \pm 0.3$ & $0.24 \pm 0.02$ & $0.220 \pm 0.008$ & $7.1 \pm 0.4$ & $7.73 \pm 0.08$ \\
\hline $\mathrm{Sm}$ & $0.11 \pm 0.01$ & $0.098 \pm 0.002$ & $2.93 \pm 0.07$ & $3.13 \pm 0.04$ & $0.055 \pm 0.004$ & $0.056 \pm 0.003$ & $1.61 \pm 0.05$ & $1.75 \pm 0.02$ \\
\hline $\mathrm{Eu}$ & $0.030 \pm 0.002$ & $0.031 \pm 0.001$ & $0.76 \pm 0.08$ & $0.83 \pm 0.01$ & $0.013 \pm 0.001$ & $0.0137 \pm 0.0004$ & $0.49 \pm 0.02$ & $0.45 \pm 0.01$ \\
\hline Gd & $0.092 \pm 0.003$ & $0.097 \pm 0.002$ & $3.2 \pm 0.1$ & $3.16 \pm 0.05$ & $0.038 \pm 0.002$ & $0.0396 \pm 0.0009$ & $1.79 \pm 0.04$ & $1.72 \pm 0.03$ \\
\hline $\mathrm{Tb}$ & $0.0139 \pm 0.0008$ & $0.0135 \pm 0.0006$ & $0.50 \pm 0.03$ & $0.48 \pm 0.01$ & $0.0090 \pm 0.0004$ & $0.0085 \pm 0.0004$ & $0.24 \pm 0.01$ & $0.250 \pm 0.008$ \\
\hline Dy & $0.071 \pm 0.002$ & $0.070 \pm 0.002$ & $2.41 \pm 0.04$ & $2.42 \pm 0.05$ & $0.033 \pm 0.003$ & $0.036 \pm 0.002$ & $1.16 \pm 0.05$ & $1.25 \pm 0.05$ \\
\hline Ho & $0.0136 \pm 0.0005$ & $0.0134 \pm 0.0002$ & $0.45 \pm 0.04$ & $0.46 \pm 0.01$ & $0.0082 \pm 0.0006$ & $0.0079 \pm 0.0002$ & $0.25 \pm 0.02$ & $0.229 \pm 0.003$ \\
\hline $\mathrm{Er}$ & $0.035 \pm 0.002$ & $0.034 \pm 0.001$ & $1.07 \pm 0.08$ & $1.14 \pm 0.06$ & $0.018 \pm 0.001$ & $0.0166 \pm 0.0003$ & $0.52 \pm 0.02$ & $0.58 \pm 0.01$ \\
\hline $\mathrm{Tm}$ & $0.0050 \pm 0.0002$ & $0.0046 \pm 0.0002$ & $0.14 \pm 0.01$ & $0.151 \pm 0.002$ & $0.0027 \pm 0.0002$ & $0.0029 \pm 0.0001$ & $0.075 \pm 0.003$ & $0.075 \pm 0.003$ \\
\hline $\mathrm{Yb}$ & $0.021 \pm 0.001$ & $0.022 \pm 0.001$ & $0.81 \pm 0.06$ & $0.81 \pm 0.02$ & $0.017 \pm 0.001$ & $0.0165 \pm 0.0004$ & $0.43 \pm 0.02$ & $0.41 \pm 0.01$ \\
\hline $\mathrm{Lu}$ & $0.0024 \pm 0.0001$ & $0.0026 \pm 0.0001$ & $0.13 \pm 0.01$ & $0.130 \pm 0.007$ & $0.0022 \pm 0.0002$ & $0.0023 \pm 0.0001$ & $0.056 \pm 0.002$ & $0.061 \pm 0.002$ \\
\hline
\end{tabular}


Table 7

Relative extraction efficiency of microwave procedure to conventional procedure $(\%)$

\begin{tabular}{|c|c|c|c|c|}
\hline \multirow{2}{*}{ REEs } & \multicolumn{4}{|c|}{ Extractant } \\
\hline & $\mathrm{CaCl}_{2}$ & EDTA & $\mathrm{CH}_{3} \mathrm{COOH}$ & $\mathrm{HCl}$ \\
\hline $\mathrm{Y}$ & 107 & 106 & 104 & 108 \\
\hline $\mathrm{La}$ & 105 & 97.8 & 95.9 & 103 \\
\hline $\mathrm{Ce}$ & 104 & 102 & 97.6 & 91.8 \\
\hline $\operatorname{Pr}$ & 95.8 & 98.2 & 109 & 108 \\
\hline $\mathrm{Nd}$ & 98.0 & 107 & 91.7 & 109 \\
\hline $\mathrm{Sm}$ & 89.1 & 107 & 102 & 109 \\
\hline $\mathrm{Eu}$ & 103 & 109 & 105 & 91.8 \\
\hline $\mathrm{Gd}$ & 105 & 98.8 & 104 & 96.1 \\
\hline $\mathrm{Tb}$ & 97.1 & 96.0 & 94.4 & 104 \\
\hline Dy & 98.6 & 100 & 109 & 108 \\
\hline Ho & 98.5 & 102 & 96.3 & 91.6 \\
\hline $\mathrm{Er}$ & 97.1 & 107 & 92.2 & 112 \\
\hline $\mathrm{Tm}$ & 92.0 & 108 & 107 & 100 \\
\hline $\mathrm{Yb}$ & 105 & 100 & 97.1 & 95.3 \\
\hline $\mathrm{Lu}$ & 108 & 100 & 105 & 109 \\
\hline
\end{tabular}

Table 8

Correlation coefficients between extractable REEs from soils by microwave extraction method using different extractants, and REEs in wheat shoots and roots $(n=15)$

\begin{tabular}{|c|c|c|c|c|c|c|c|c|}
\hline \multirow[t]{2}{*}{ REEs } & \multicolumn{4}{|l|}{ Shoots } & \multicolumn{4}{|l|}{ Roots } \\
\hline & $\mathrm{CaCl}_{2}$ & EDTA & $\mathrm{CH}_{3} \mathrm{COOH}$ & $\mathrm{HCl}$ & $\mathrm{CaCl}_{2}$ & EDTA & $\mathrm{CH}_{3} \mathrm{COOH}$ & $\mathrm{HCl}$ \\
\hline Y & $0.8698^{* *}$ & $0.5426^{*}$ & $0.8671^{* *}$ & $0.6373^{*}$ & 0.1568 & 0.5103 & $0.5978^{*}$ & 0.2093 \\
\hline $\mathrm{La}$ & $0.8940^{* *}$ & 0.4522 & $0.6966^{* *}$ & $0.5652^{*}$ & 0.4904 & 0.4666 & $0.6265^{*}$ & 0.1096 \\
\hline $\mathrm{Ce}$ & $0.8448^{* *}$ & 0.4732 & $0.7152^{* *}$ & $0.6534^{* *}$ & 0.2953 & 0.5106 & 0.4295 & 0.2007 \\
\hline $\operatorname{Pr}$ & $0.8013^{* *}$ & 0.4498 & $0.7940^{* *}$ & $0.6139^{*}$ & 0.2081 & $0.5410^{*}$ & 0.426 & 0.1577 \\
\hline $\mathrm{Nd}$ & $0.7479^{* *}$ & $0.5412^{*}$ & $0.7769^{* *}$ & 0.4972 & 0.3514 & 0.4823 & $0.6317^{*}$ & 0.2605 \\
\hline $\mathrm{Sm}$ & $0.8336^{* *}$ & $0.5879^{*}$ & $0.8105^{* *}$ & $0.6413^{* *}$ & 0.1608 & $0.6454^{* *}$ & $0.6539^{* *}$ & 0.3326 \\
\hline $\mathrm{Eu}$ & $0.8996^{* *}$ & $0.7783^{* *}$ & $0.7437^{* *}$ & $0.6205^{*}$ & 0.4111 & $0.5986^{*}$ & $0.7574^{* *}$ & $0.5938^{*}$ \\
\hline $\mathrm{Gd}$ & $0.8516^{* *}$ & $0.5475^{*}$ & $0.8552^{* *}$ & $0.7015^{* *}$ & 0.2283 & 0.4972 & $0.6083^{*}$ & 0.2642 \\
\hline $\mathrm{Tb}$ & $0.7366^{* *}$ & $0.5563^{*}$ & $0.7900^{* *}$ & $0.6595^{* *}$ & 0.3818 & $0.6344^{* *}$ & $0.5253^{*}$ & 0.3187 \\
\hline Dy & $0.8533^{* *}$ & $0.5573^{*}$ & $0.8651^{* *}$ & $0.6287^{*}$ & 0.2611 & $0.5557^{*}$ & $0.5482^{*}$ & 0.3276 \\
\hline Ho & $0.8182^{* *}$ & $0.5784^{*}$ & $0.8114^{* *}$ & $0.5702^{*}$ & 0.2816 & $0.5143^{*}$ & $0.6963^{* *}$ & 0.3458 \\
\hline $\mathrm{Er}$ & $0.8911^{* *}$ & $0.5601^{*}$ & $0.7757^{* *}$ & $0.5824^{*}$ & 0.2787 & 0.4513 & $0.7558^{* *}$ & 0.2966 \\
\hline $\mathrm{Tm}$ & $0.6588^{* *}$ & $0.5390^{*}$ & $0.8118^{* *}$ & 0.5123 & 0.2117 & 0.3573 & 0.3945 & 0.3099 \\
\hline $\mathrm{Yb}$ & $0.8127^{* *}$ & $0.5424^{*}$ & 0.6506 & 0.4869 & 0.2020 & 0.3204 & $0.6768^{* *}$ & 0.3135 \\
\hline $\mathrm{Lu}$ & $0.6514^{* *}$ & $0.5396^{*}$ & $0.6704^{* *}$ & $0.5309^{*}$ & 0.3207 & 0.3553 & $0.6135^{*}$ & 0.3190 \\
\hline
\end{tabular}

${ }^{*}$ Significant at 0.05 .

*** Significant at 0.01 .

better precision. Therefore, the single microwave extraction method could be considered as a useful alternative to the conventional single extraction procedure in the study of environmental impact of REEs.

\section{Acknowledgements}

This work was funded by the Nation Natural Science Foundation of China (grant no. 40171086, 20237010).

\section{References}

Cid, B.P., Albores, A.F., Gomez, E.F., Lopez, E.F., 2001. Use of microwave single extraction for metal fractional in sewage sludge samples. Anal. Chim. Acta 431, 209-218.

Das, A.K., Chakraborty, R., Cervera, M.L., Guardia, M., 1995. Metal speciation in solid matrices. Talanta 42, 10071030.

Ginepro, M., Gulmini, M., Ostacoli, G., Zelano, V., 1996. Microwave desorption treatment after the oxidation step in Tessier's sequential extraction scheme. Int. J. Environ. Anal. Chem. 63, 147-152. 
Hu, X., Ding, Z., Chen, Y., Wang, X., Dai, L., 2002. Bioaccumulation of lanthanum and cerium and their effects on the growth of wheat (Triticum aestivum L.) seedlings. Chemosphere 48, 621-629.

Ichihashi, H., Morita, H., Tatsukawa, R., 1992. Rare earth elements (REEs) in naturally grown plants in relation to their variation in soils. Environ. Pollut. 76, 157-162.

Jayaraman, S., Pruell, R.J., McKinney, R., 2001. Extraction of organic contaminants from marine sediments and tissues using microwave energy. Chemosphere 44, 181-191.

Jin, Q., Liang, F., Zhang, H., Zhao, L., Huan, H., Song, D., 1999. Application of microwave techniques in analytical chemistry. Trends Anal. Chem. 18, 479-484.

Lau, L.S., 1988. Handbook for Soil Agriculture and Chemical Analysis. Agriculture Press, Beijing, China. pp. 236-386.

Li, F., Shan, X., Zhang, T., Zhang, S., 1998. Evaluation of plant availability of rare earth elements in soils by chemical fraction and multiple regression analysis. Environ. Pollut. 102, 269-277.

Parkes, G.M.B., Barnes, P.A., 1999. Microwave differential thermal analysis in the investigation of thermal transitions in materials. Anal. Chem. 71, 5026-5033.

Quevauiller, Ph., Rauret, G., Griepink, B., 1993. Conclusions of the workshop: single and sequential extraction in sediments and soils. Int. J. Environ. Anal. Chem. 57, 135150.

Rauret, G., 1998. Extraction procedures for the determination of heavy metals in contaminated soil and sediment. Talanta 46, 449-455.
Tessier, A., Campbell, P.G.C., Bisson, M., 1979. Sequential extraction procedure for the speciation of particulate trace metals. Anal. Chem. 51, 231-235.

Tu, Q., Wang, X.R., Tian, L.Q., Dai, L.M., 1994. Bioaccumulation of the rare earth elements lanthanum, gadolinium and yttrium in carp (Cyprinus carpio). Environ. Pollut. 85, 345350.

Ure, A.M., Quevauviller, Ph., Munteau, H., Griepink, B., 1993. Speciation of heavy metal in soils and sediments. An account of the improvement and harmonization of extraction techniques undertaken under the auspices of the BCR of the commission of the European Communities. Int. J. Environ. Anal. Chem. 51, 135-151.

Wang, Z., Shan, X., Zhang, S., 2001. Comparison of speciation and bioavailability of rare earth elements between wet rhizoshpere soil and air-dried bulk soil. Anal. Chim. Acta 441, 147-156.

Wang, Z., Shan, X., Zhang, S., 2002. Comparison between fractionation and bioavailability of trace elements in rhizosphere and bulk soil. Chemosphere 48, 1163-1171.

Wyttenbach, A., Furrer, C., Schleppi, P., Tobler, L., 1998. Rare earth elements in soil and in soil-grown plants. Plant Soil 199, 267-273.

Zhang, S., Shan, X., 1997. The determination of rare earth elements in soil by inductively coupled plasma mass spectrometry. At. Spectrosc. 19, 140-144.

Zhang, S., Shan, X., 2001. Speciation of rare earth elements in soil and accumulation by wheat with rare earth fertilizer application. Environ. Pollut. 112, 395-405. 